\title{
Kursi Kerja Ergonomis PT XYZ
}

\author{
Fu'ad Kautsar $^{1 *}$, Novira Kathrina Dewi ${ }^{2}$ \\ ${ }^{12}$ Prodi Teknik Industri, Universitas Merdeka Malang \\ *Korespondensi Penulis, E-mail: fuad.kautsar@unmer.ac.id
}

\author{
Diterima : 25 Oktober 2020 \\ Direvisi : 3 November 2020 \\ Disetujui : 19 November 2020
}

Abstrak

\begin{abstract}
Posisi kerja yang kurang baik dapat menyebabkan kelelahan kerja dan berakibat timbulnya dampak tidak langsung berupa keluhan sakit pada bagian tubuh seperti pegal-pegal, nyeri punggung, leher kaku, cepat lelah, dan lain sebagainya sehingga mempengaruhi kinerja dan hasil produksi. Dampak tidak langsung tersebut telah dirasakan oleh beberapa karyawan PT XYZ. . Terdapat tiga bentuk kursi kerja yang berada di ruangan departemen non proses. Ergonomi merupakan suatu ilmu, seni dan teknologi yang berupaya untuk menyerasikan alat, cara dan lingkungan kerja terhadap kemampuan, kebolehan dan segala keterbatasan manusia, sehingga manusia dapat berkarya secara optimal tanpa pengaruh buruk dari pekerjaannya. Data antropometri dapat digunakan untuk mendesain pakaian, tempat kerja, lingkungan kerja, mesin, alat dan sarana kerja serta produk-produk untuk konsumen. hasil perhitungan melalui REBA ( Rapid Entire Body Assessment) worksheet dapat diketahui kursi jenis 2 dan 3 memiliki nilai REBA yang tinggi yaitu 9 yang berarti High Risk dan perlu untuk investigasi khusus dan perubahan posisi duduk / jenis kursi yang digunakan.. Hasil perhitungan dimensi kursi yang sudah diuji distribusi dan normalitasnya, diharapkan bisa memenuhi kebutuhan pekerja dan mengurangi resiko kecelakaan bagi pekerja. Dengan adanya penelitian ini mengharapkan kewaspadaan bagi pekerja untuk lebih memperhatikan ergonomi ditempat kerja terutama posisi duduk dalam bekerja.
\end{abstract}

Kata kunci: Kursi kerja, Ergonomi, REBA

\section{Pendahuluan}

Seiring berjalannya waktu, kebutuhan manusia akan fasilitas bekerja yang nyaman juga meningkat, manusia dan seluruh aktifitas perkantoran adalah faktor paling penting dalam menentukan kebutuhan ruang gerak yang nyaman dalam bekerja / Human Centered Design [1] Posisi kerja yang kurang baik dapat menyebabkan kelelahan kerja dan berakibat timbulnya dampak tidak langsung berupa keluhan sakit pada bagian tubuh seperti pegal-pegal, nyeri punggung, leher kaku, cepat lelah, dan lain sebagainya sehingga mempengaruhi kinerja dan hasil produksi.[2] Dampak tidak langsung tersebut telah dirasakan oleh beberapa karyawan PT XYZ yang merupakan salah satu perusahaan food and Beverages di Indonesia. Fokus penelitian ini adalah kursi kerja karyawan Departemen Non Proses yang terdiri dari 4 (empat) sub departemen yaitu HSE (Health - Safety - Environment), PPIC (Production Planning Inventory Control), Administrasi dan Personalia. Terdapat tiga bentuk kursi kerja yang berada di ruangan departemen non proses seperti yang dapat dilihat pada gambar 1 dibawah ini. 


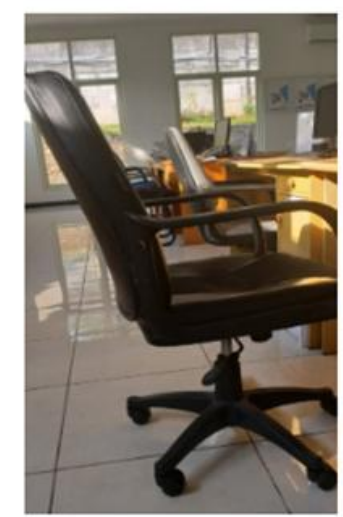

Kursi Tipe - 1

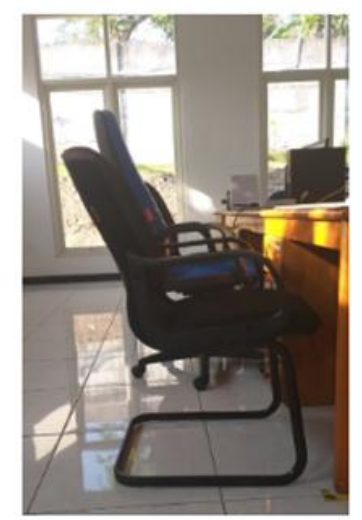

Kursi Tipe - 2

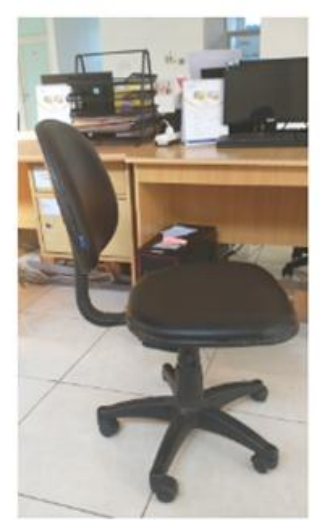

Kursi Tipe - 3

Gambar 1. Tipe kursi

Kursi tipe - 1 memiliki roda, bantalan lengan, bantalan punggung dan tuas untuk mengatur ketinggian. Bentuk kursi tipe -2 yakni tidak memiliki roda, namum memiliki bantalan punggung dan lengan. Sedangkan kursi tipe -3 beroda, memiliki tuas pengatur ketinggian dan memiliki bantalan pada punggung serta lengan. Sebagian besar karyawan menggunakan kursi tipe 3 dalam bekerja. Penelitian ini bertujuan untuk mengevaluasi resiko kursi kerja dengan metode REBA (Rapid Entire Body Assessment) yang merupakan metode dalam bidang ergonomi yang digunakan secara cepat untuk menilai postur leher, punggung, lengan, pergelangan tangan, dan kaki seorang pekerja [3] kemudian mengusulkan dimensi kursi kerja yang sesuai kaidah ergonomi.

Ergonomi merupakan suatu ilmu, seni dan teknologi yang berupaya untuk menyerasikan alat, cara dan lingkungan kerja terhadap kemampuan, kebolehan dan segala keterbatasan manusia, sehingga manusia dapat berkarya secara optimal tanpa pengaruh buruk dari pekerjaannya [4] Data antropometri dapat digunakan untuk mendesain pakaian, tempat kerja, lingkungan kerja, mesin, alat dan sarana kerja serta produk-produk untuk konsumen. [5]

\section{Metode Penelitian}

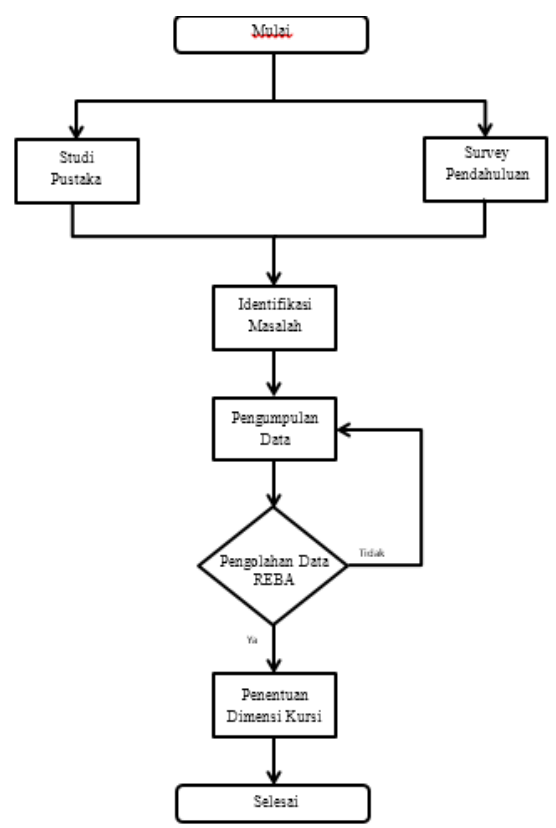

Gambar 2. Diagram Alir Penelitian 


\section{Hasil}

\subsection{Perhitungan REBA Kursi Tipe - 1}

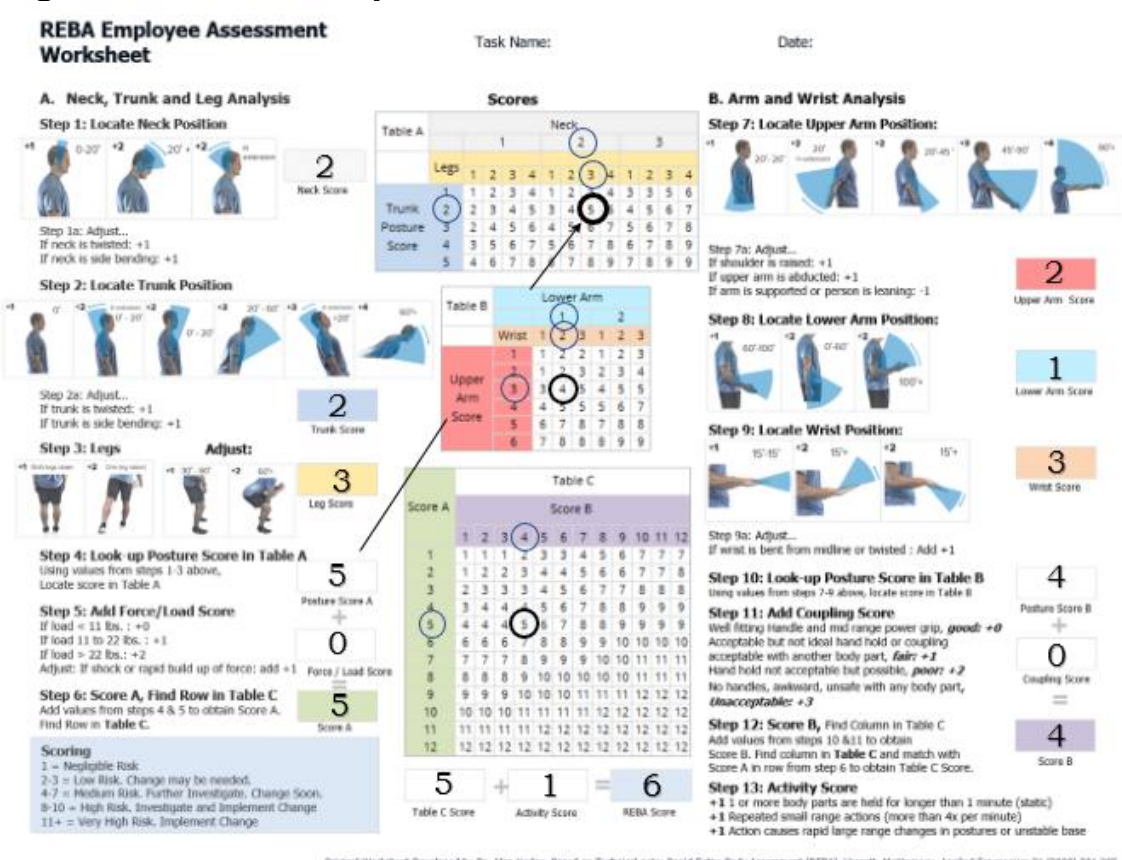

Gambar 3. Perhitungan REBA Kursi Tipe - 1

Hasil akhir menunjukkan pada Level medium risk, skor akhir menunjukkan nilai 6 yang mengindikasi bahwa posisi/postur tersebut memerlukan tindakan perbaikan untuk jangka waktu yg lama atau tidak dalam waktu dekat.

\subsection{Perhitungan REBA Kursi Tipe - 2}

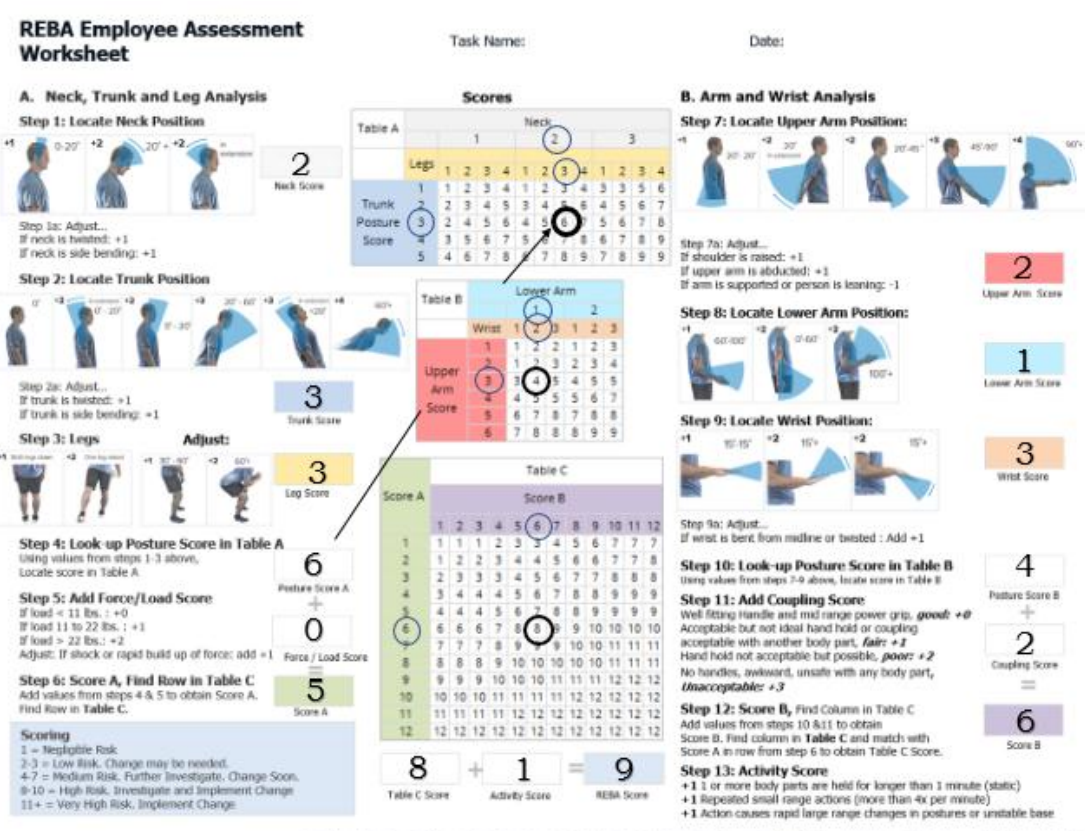

Gambar 4. Perhitungan REBA Kursi Tipe -2 
Hasil akhir menunjukkan pada Level high risk, skor akhir menunjukkan nilai 9 yang mengindikasi bahwa posisi/postur tersebut memerlukan tindakan perbaikan segera.

\subsection{Perhitungan REBA Kursi Tipe - 3}

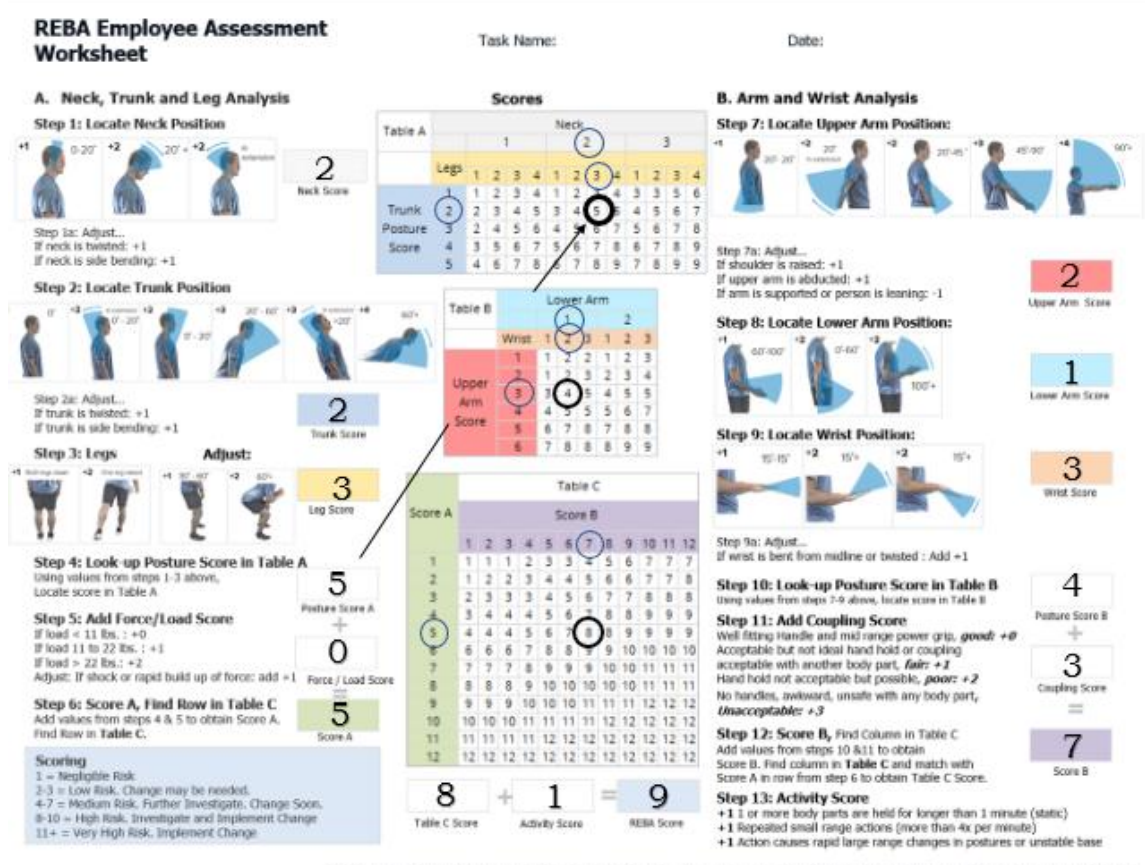

Gambar 5. Perhitungan REBA Kursi Tipe - 3

Hasil akhir menunjukkan pada Level high risk, skor akhir menunjukkan nilai 9 yang mengindikasi bahwa posisi/postur tersebut memerlukan tindakan perbaikan segera.

\subsection{Data Antropometri}

Setelah menghitung dengan REBA langkah selanjutnya adalah pengambilan data. Diambil 10 data karyawan sebagai berikut :

Tabel 1 Data Antropometri Karyawan

\begin{tabular}{|c|c|c|c|c|}
\hline No & $\begin{array}{l}\text { Tinggi Bahu } \\
\text { Duduk }\end{array}$ & $\begin{array}{l}\text { Tinggi siku } \\
\text { duduk }\end{array}$ & $\begin{array}{l}\text { Lebar Pinggul } \\
\text { duduk }\end{array}$ & $\begin{array}{c}\text { Panjang } \\
\text { Poptieal }\end{array}$ \\
\hline 1 & 49 & 16 & 41,2 & 45,1 \\
\hline 2 & 47 & 18 & 38 & 45 \\
\hline 3 & 53 & 25 & 48 & 52 \\
\hline 4 & 52 & 25,3 & 39 & 46,4 \\
\hline 5 & 54 & 27 & 45 & 45,3 \\
\hline 6 & 50,2 & 24,5 & 45,9 & 49 \\
\hline 7 & 51 & 24,5 & 38,4 & 46,2 \\
\hline 8 & 49 & 25,5 & 36,5 & 43,5 \\
\hline 9 & 48,5 & 22 & 37,5 & 47 \\
\hline 10 & 52 & 23,3 & 38,5 & 44,3 \\
\hline
\end{tabular}




\section{Pembahasan}

\subsection{Perhitungan REBA}

TABEL 2 REKAPITULASI PERHITUNGAN REBA

\begin{tabular}{|c|c|c|l|}
\hline $\begin{array}{c}\text { Tipe } \\
\text { Kursi }\end{array}$ & $\begin{array}{c}\text { Hasil } \\
\text { Akhir }\end{array}$ & Level & \multicolumn{1}{c|}{ Keterangan } \\
\hline Tipe -1 & 6 & Medium Risk & Perlu perbaikan tidak dalam waktu dekat \\
\hline Tipe -2 & 9 & High Risk & Perlu perbaikan secepatnya \\
\hline Tipe -3 & 9 & High Risk & Perlu perbaikan secepatnya \\
\hline
\end{tabular}

Dari hasil perhitungan melalui REBA ( Rapid Entire Body Assessment ) worksheet dapat diketahui kursi jenis 2 dan 3 memiliki nilai REBA yang tinggi yaitu 9 yang berarti High Risk dan perlu untuk investigasi khusus dan perubahan posisi duduk / jenis kursi yang digunakan.

\subsection{Uji Normalitas}

Dalam uji normalitas data antropometri pada penelitian ini, tingkat kepercayaan yang digunakan $95 \%$ dan $\alpha=0,05$. Penggunaan tingkat kepercayaan 95\% dikarenakan nilai ini memberikan keseimbangan antara presisi (yang ditunjukkan dengan lebar selang kepercayaan) dan reliabilitas (yang ditunjukkan dengan tingkat kepercayaan).Kemudian diuji apakah data tersebut berdistribusi normal atau tidak dengan rincian sebagai berikut:

1. Uji Hipotesis

$\mathrm{H}_{0}$ : Data berdistribusi normal

$\mathrm{H}_{1}$ : Data tidak berdistribusi normal

2. Uji Statistik dengan Uji Kolmogorov-Smirnov

Jika $\mathrm{D}_{\max }>\alpha$, maka $\mathrm{H}_{0}$ diterima

Jika $\mathrm{D}_{\max }<\alpha$, maka $\mathrm{H}_{0}$ ditolak

3. Dari data pengolahan perhitungan Uji Kolmogotov-Sminorv dengan Microsoft Excel didapatkan nilai signifikan 0,161 untuk Tbd, 0,148 untuk Tsd, 0,272 untuk Tpd dan 0,202 untuk Pp.Dari hasil perhitungan tersebut, $\mathrm{D}_{\max }>\alpha$, maka $\mathrm{H}_{0}$ diterima, artinya data berdistribusi normal yang berarti data dapat diolah.

Setelah dihitung menggunakan Ms. Excel data lebih lengkap terdapat pada Tabel 3 sebagai berikut :

Tabel 3 Uji Normalitas dengan Kolgomorov-Smirnov

\begin{tabular}{|l|l|l|l|c|l|}
\hline No & Pengukuran & $\mathrm{N}$ & $\mathrm{D}_{\max }$ & $\alpha$ & Keterangan \\
\hline 1 & Tinggi Bahu Duduk (Tbd) & 10 & 0,161 & 0,05 & Data Normal \\
\hline 2 & Tinggi Siku Duduk (Tsd) & 10 & 0,148 & 0,05 & Data Normal \\
\hline 3 & Lebar Pinggul Duduk (Lpd) & 10 & 0,272 & 0,05 & Data Normal \\
\hline 4 & Panjang Poptieal (Pp) & 10 & 0,202 & 0,05 & Data Normal \\
\hline
\end{tabular}

\subsection{Uji Keseragaman Data}

Dalam uji keseragaman data antropometri penelitian ini tingkat kepercayaan yang digunakan $95 \%$. Adapun salah satu perhitungan uji keseragaman data lebar pinggul duduk adalah sebagai berikut: 
1. Rata -rata $(\bar{X})$

$$
\bar{x}=\sum_{i=1}^{n=10} x_{i}=\frac{41,2+38+48+39+45+\cdots+38,5}{10}=40,8
$$

2. Standart Deviasi $(\sigma)$

$$
\begin{aligned}
& \sigma=\sqrt{\frac{\sum_{i=1}^{n=10}\left(x_{i}-\bar{x}\right)^{2}}{N-1}} \\
& \sigma=\sqrt{\frac{(41,2-40,8)^{2}+(38-40,8)^{2}+\cdots+(38,5-40,8)^{2}}{10-1}}=4,04
\end{aligned}
$$

3. BKA dan BKB

Kemudian menentukan batas kontrol atas (BKA) dan batas kontrol bawah (BKB) untuk lebar pinggul duduk adalah:

Batas Kontrol Atas (BKA)

$$
\begin{aligned}
\mathrm{BKA} & =\bar{x}+k(\sigma) \\
& =40,8+2(4,04) \\
& =48,89
\end{aligned}
$$

Batas Kontrol Bawah (BKB)

$$
\mathrm{BKB} \quad \begin{aligned}
& \bar{x}-k(\sigma) \\
& =40,8-2(4,04) \\
& =32,71
\end{aligned}
$$

Karena nilai $\bar{x}=40,8$ itu berada diantara nilai batas kontrol atas dan nilai batas kontrol bawah, maka data lebar pinggul dinyatakan seragam.

Adapun hasil uji keseragaman data antropometri lainnya dapat dilihat pada tabel 4 sebagai berikut:

Tabel 4 Pengukuran Keseragaman Data Antropometri

\begin{tabular}{|l|l|l|l|l|l|l|}
\hline No & Pengukuran & $\bar{x}$ & $\sigma$ & BKA & BKB & Keterangan \\
\hline 1 & $\begin{array}{l}\text { Tinggi Bahu } \\
\text { Duduk } \\
\text { (Tbd) }\end{array}$ & 50,57 & 2,21 & 54,99 & 46,15 & $\begin{array}{l}\text { Data } \\
\text { Seragam }\end{array}$ \\
\hline 2 & $\begin{array}{l}\text { Tinggi Siku } \\
\text { Duduk } \\
\text { (Tsd) }\end{array}$ & 23,11 & 3,51 & 30,13 & 16,09 & $\begin{array}{l}\text { Data } \\
\text { Seragam }\end{array}$ \\
\hline 3 & $\begin{array}{l}\text { Lebar } \\
\text { Pinggul } \\
\text { Duduk } \\
\text { (Lpd) }\end{array}$ & 40,8 & 4,04 & 48,89 & 32,71 & $\begin{array}{l}\text { Data } \\
\text { Seragam }\end{array}$ \\
\hline 4 & $\begin{array}{l}\text { Panjang } \\
\text { Poptieal } \\
\text { (Pp) }\end{array}$ & 46,38 & 2,49 & 51,37 & 41,38 & $\begin{array}{l}\text { Data } \\
\text { Seragam }\end{array}$ \\
\hline
\end{tabular}




\subsection{Uji Kecukupan Data Antropometri}

Dalam uji kecukupan data antropometri penelitian ini tingkat kepercayaan yang digunakanv 95\% dan tingkat ketelitian sebesar 5\%. Untuk perhitungan uji kecukupan data antropometri lebar pinggul duduk adalah sebagai berikut :

$$
\begin{aligned}
& N^{I}=\left[\frac{\frac{k}{s} \sqrt{N\left(\sum_{i=1}^{n=10} x_{i}^{2}\right)-\left(\sum_{i=1}^{n=10} x_{i}\right)^{2}}}{\left(\sum_{i=1}^{n=10} x_{i}\right)}\right] \\
& N^{I}=\left[\frac{\frac{2}{0,05} \sqrt{10(16793,56)-(408)^{2}}}{(408)}\right] \\
& N^{I}=\left[\frac{1534,46}{408}\right]=3,761 \approx 4
\end{aligned}
$$

Adapun hasil uji kecukupan data antropometri lainnya dapat dilihat pada tabel 5 sebagai berikut:

Tabel 5 Pengukuran Kecukupan Data Antropometri

\begin{tabular}{|l|l|l|l|l|}
\hline No & Pengukuran & $N$ & $N^{I}$ & $\begin{array}{l}\text { Keterangan } \\
\left(N^{I}<N\right)\end{array}$ \\
\hline 1 & Tinggi Bahu Duduk & 10 & 2 & Data Cukup \\
\hline 2 & Tinggi Siku Duduk & 10 & 6 & Data Cukup \\
\hline 3 & Lebar Pinggul Duduk & 10 & 4 & Data Cukup \\
\hline 4 & Panjang Poptieal & 10 & 2 & Data Cukup \\
\hline
\end{tabular}

\subsection{Ukuran Persentil}

Pengukuran persentil untuk perancangan suatu benda kerja ada 3 yaitu $5^{\text {th }}\left(P_{5}\right)$ untuk ukuran persentil kecil, $50^{\text {th }}\left(P_{50}\right)$ untuk ukuran persentil rata-rata dan $95^{\text {th }}\left(P_{95}\right)$ untuk ukuran persentil besar. Dalam penelitian ini menggunakan $P_{50}$ dikarenakan $P_{50}$ adalah persentil rata-rata yang diharapkan hasil perancangan kursi kerja sesuai dengan dimensi yang ada (tidak terlalu kecil atau terlalu besar).

Berikut perhitungan untuk $\mathrm{P}_{50}$ pada data antropometri lebar pinggul duduk :

$$
\mathrm{P}_{50}=\bar{x}=40,8
$$
berikut :

Adapun perhitungan persentil yang digunakan dapat dilihat pada tabel 5.4 sebagai

Tabel 6 Pengukuran Persentil Perancangan Kursi

\begin{tabular}{|l|l|c|}
\hline No & Pengukuran & $\mathrm{P}_{50}(\mathrm{~cm})$ \\
\hline 1 & Tinggi Bahu Duduk & 50,57 \\
\hline 2 & Tinggi Siku Duduk & 23,11 \\
\hline 3 & Lebar Pinggul Duduk & 40,8 \\
\hline 4 & Panjang Poptieal & 46,38 \\
\hline
\end{tabular}

Berdasarkan tabel diatas bahwa tinggi bahu duduk untuk populasi karyawan di PT $X Y Z$ menggunakan $P_{50}=50,57 \mathrm{~cm}$, tinggi siku duduk menggunakan $P_{50}=23,11 \mathrm{~cm}$, lebar pinggul duduk menggunakan $\mathrm{P}_{50}=40,8 \mathrm{~cm}$, dan panjang poptieal menggunakan $P_{50}=46,38 \mathrm{~cm}$. 


\subsection{Dimensi Kursi Kerja Ergonomis}

Setelah dilakukan investigasi dan analisa terhadap kursi kerja karyawan pada PT

XYZ maka dilakukan suatu perancangan kursi kerja berdasarkan kaidah ergonomi dan perhitungan persentil dengan sebagai berikut :

1. Tinggi dudukan

Tinggi dudukan harus lebih tinggi dari panjang popliteal (dimensi panjang dari ujung pantat ke bagian belakang lutut dalam keadaan duduk). Dalam penentuan ukuran tinggi dudukan menggunakan dimensi panjang poptieal. Adapun kriteria yang harus dipenuhi yaitu :

a. Kaki bagian bawah harus dapat membentuk sudut antara $5-30^{\circ}$ relatif terhadap vertikal

b. Sudut antara paha dan tubuh sekitar $95-120^{\circ}$.

Dalam kasus ini kursi tetap menggunakan tuas untuk naik/turun yang disesuaikan dengan tinggi kaki pekerja. Agar lebih efisien dan maksimal dalam penggunaannya.

\section{Tinggi Sandaran}

Tinggi sandaran yang baik harus dapat menahan $60-80 \%$ dari tinggi bahu pekerja ketika duduk. Akan lebih baik jika bentuk sandaran punggung dibuat menyesuaikan bentuk lengkungan pada tulang belakang. Dimensi yang digunakan sebagai ukuran tinggi sandaran adalah dimensi tinggi bahu duduk. Namun saat ini kursi yang tersedia sudah memiliki sandaran punggung yang hanya sampai $1 / 2-3 / 4$ punggung. Namun lebih baik jika sandaran punggung bisa menyandarkan keseluruhan punggung, yakni sampai tulang leher.

\section{Lebar Dudukan}

Lebar dudukan harus $10-30 \%$ lebih besar dari pantat pekerja. Hal ini dimaksudkan untuk allowance space bagi pekerja saat duduk. Penentuan lebar dudukan diambil dari dimensi antropometri lebar pinggul duduk.

\subsection{Penentuan Ukuran Kursi}

Setelah melakukan perhitungan ukuran persentil diperoleh, maka langkah selanjutnya adalah menentukan ukuran kursi yang dapat dilihat pada tabel 5.5 berikut :

Tabel 7 Dimensi Kursi Baru

\begin{tabular}{|l|l|c|}
\hline No & Pengukuran & Ukuran $(\mathrm{cm})$ \\
\hline 1 & Tinggi Sandaran & 50,57 \\
\hline 2 & Tinggi Sandaran Siku & 23,11 \\
\hline 3 & Lebar Alas kursi & 40,8 \\
\hline 4 & Tinggi alas Kursi & 46,38 \\
\hline
\end{tabular}

\section{Kesimpulan}

Dari hasil penelitian diatas dapat diketahui bahwa :

a. Lingkungan fisik dan fasilitas kerja yang ada di PT XYZ belum sepenuhnya memenuhi kaidah ergonomi dikarenakan masih adanya keluhan - keluhan dari pekerja mengenai kesehatan mereka akibat terlalu lama duduk di kursi yang telah tersedia. Namun juga kesalahan tidak pada fasilitas yang ada, pekerja juga ikut andil dalam hal penggunaan/pemanfaatan fasilitas kerja sudah dimaksimalkan atau belum. Dalam hal ini pekerja perkantoran banyak melakukan kegiatan statis di meja komputer. Apapila kita lebih memperhatikan bagaimana posisi duduk dan mengoptimalkan sesuai dengan dimensinya, maka penyakit akibat kesalahan posisi duduk tidak muncul. Mungkin untuk tahun pertama 
hingga ke 3 masih bisa diremehkan, namun usia manusia makin lama makin berkurang serta struktur tulang dan otot fungsinya juga semakin menurun.

b. Analisa REBA dari tipe kursi - 3 menunjukkan hasil high risk dimana harus dilakukan perubahan dimensi kursi kerja agar manfaat kepada pekerja lebih optimal.

c. Hasil perhitungan dimensi kursi yang sudah diuji distribusi dan normalitasnya, diharapkan bisa memenuhi kebutuhan pekerja dan mengurangi resiko kecelakaan bagi pekerja. Dengan adanya penelitian ini mengharapkan kewaspadaan bagi pekerja untuk lebih memperhatikan ergonomi ditempat kerja terutama posisi duduk dalam bekerja.

\section{Acuan Referensi}

[1] Muhammad Nur Fajri Alfata et al, (2012) Studi Ergonomi terhadap Rancangan Ruang Kerja Kantor Pemerintah Berdasarkan Antropometri Indonesia. Jurnal Permukiman Vol. 7 No. 3 pp : 126-137

[2] Billy Frans Siahaan et al (2017). Perancangan Fasilitas Kerja Yang Ergonomi Dengan Menggunakan Metode Rasional Di Dusun Serdang Bedagai Provinsi Sumatra Utara. Journal of Industrial and Manufacture Engineering, 1 (1) pp : 1-13

[3] Mochammad Rofieq et al (2019) The Work Posture Evaluation at Assembly Work Station in MSEs of Silver Jewelry Handicraft with the REBA Method. Advances in Intelligent Systems Research, volume 173. $1^{\text {st }}$ International Conference on Engineering and Management in Industrial System (ICOEMIS 2019) pp 87 - 94

[4] Akhmad Shokibi (2017) Perancangan Kursi Ergonomis Untuk Memperbaiki Posisi Kerja Pada Proses Packaging Jenang Kudus. Jurnal Rekayasa Industri, Format Volume 3. No. 1.

[5] Hendrastuti Hendro et al, (2016). Usulan perancangan Fasilitas Kerja Dengan Pendekatan Ergonomi Menggunakan Metode Rapid Entire Body Assestment (REBA) di PT Z. Jurnal Riset Industri Vol. 10 No. 1, April 2016, Hal. 1-11 